The Egyptian International Journal of Engineering Sciences \& Technology, Vol 9, No 1 (2005)

\title{
Activity-Based Costing for Evaluating Manufacture Facilities Decisic Making
}

Ibrahim m.s, m.f ElBaz, M Adel, Mesalam Y.I

\begin{abstract}
Competitiveness in industry indicates that effort is required to evaluate manufacture facilities in terms of unit cast-based approach. The. objective of this paper is to estimate the different manufacturing costs for the alternative manufacturing facilities using an activity-based cost $(A B C)$ model. First, this paper reports and discusses the implementation of the $A B C$ in manufacturing. Second, the potential effects of selecting manufacturing facilities implemented on financial structure are presented alongside a case study. The comparison of the different alternative manufacturing facilities in terms of the manufacturing costs highlight the benefits and the accuracy of using $A B C$ as a base for estimating manufacturing costs and a valuable tool for decision making procedure
\end{abstract}

